\title{
BOK promotes chemical-induced hepatocarcinogenesis in mice
}

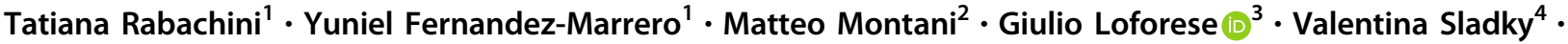 \\ Zhaoyue He $^{1} \cdot$ Daniel Bachmann ${ }^{1} \cdot$ Simone Wicki ${ }^{1} \cdot$ Andreas Villunger $^{4,5} \cdot$ Deborah Stroka $^{3} \cdot$ Thomas Kaufmann $^{1}{ }^{1}$
}

Received: 9 May 2017 / Revised: 27 September 2017 / Accepted: 12 October 2017 / Published online: 11 December 2017

(c) The Author(s) 2017. This article is published with open access

\begin{abstract}
BCL-2-related ovarian killer (BOK) is a conserved and widely expressed BCL-2 family member with sequence homology to pro-apoptotic BAX and BAK, but with poorly understood pathophysiological function. Since several members of the BCL-2 family are critically involved in the regulation of hepatocellular apoptosis and carcinogenesis we aimed to establish whether loss of BOK affects diethylnitrosamine (DEN)-induced hepatocarcinogenesis in mice. Short-term exposure to DEN lead to upregulation of BOK mRNA and protein in the liver. Of note, induction of CHOP and the pro-apoptotic BH3-only proteins PUMA and BIM by DEN was strongly reduced in the absence of BOK. Accordingly, Bok $k^{-/-}$mice were significantly protected from DEN-induced acute hepatocellular apoptosis and associated inflammation. As a consequence, $B o k^{-/}$animals were partially protected against chemical-induced hepatocarcinogenesis showing fewer and, surprisingly, also smaller tumors than WT controls. Gene expression profiling revealed that downregulation of BOK results in upregulation of genes involved in cell cycle arrest. Bok $k^{-/}$hepatocellular carcinoma (HCC) displayed higher expression levels of the cyclin kinase inhibitors $\mathrm{p} 19^{\mathrm{INK} 4 \mathrm{~d}}$ and $\mathrm{p} 21^{\mathrm{cip} 1}$. Accordingly, hepatocellular carcinoma in $\mathrm{Bok}^{-/-}$animals, BOK-deficient human HCC cell lines, as well as non-transformed cells, showed significantly less proliferation than BOK-proficient controls. We conclude that BOK is induced by DEN, contributes to DEN-induced hepatocellular apoptosis and resulting hepatocarcinogenesis. In line with its previously reported predominant localization at the endoplasmic reticulum, our findings support a role of BOK that links the cell cycle and cell death machineries upstream of mitochondrial damage.
\end{abstract}

Edited by G. Melino

Electronic supplementary material The online version of this article (https://doi.org/10.1038/s41418-017-0008-0) contains supplementary material, which is available to authorized users.

$\triangle$ Thomas Kaufmann

thomas.kaufmann@pki.unibe.ch

1 Institute of Pharmacology, University of Bern, Inselspital, INO-F, CH-3010 Bern, Switzerland

2 Institute of Pathology, University of Bern, Murtenstrasse 31, CH3008 Bern, Switzerland

3 Department of Clinical Research, Visceral and Transplantation Surgery, University of Bern, Murtenstrasse 35, CH-3008 Bern, Switzerland

4 Division of Developmental Immunology, BIOCENTER, Medical University of Innsbruck, Innrain 80/II, 6020 Innsbruck, Austria

5 Tyrolean Cancer Research Institute, Innrain 66, 6020 Innsbruck, Austria

\section{Introduction}

Hepatocellular carcinoma (HCC) is the most frequent liver cancer and among the most lethal and prevalent malignancies in humans [1]. Several risk factors are associated with the development of HCC. These include chronic infections with hepatitis viruses (HBV or HCV), exposure to aflatoxin-B1, polycystic aromatic hydrocarbons and nitrosamines, as well as alcoholic and non-alcoholic fatty liver disease [2]. HCC can be triggered in experimental animal models with a single postnatal injection of the chemical carcinogen diethylnitrosamine (DEN) [3]. The intense inflammatory response triggered by the hepatic injury leads to the immune surveillance of the damaged tissue [4]. However, this response also further stimulates tumor development via compensatory hepatocyte proliferation [5, 6]. Apoptotic cell death is recognized as a crucial event in chemical-induced hepatocyte cell death and HCC development [7]. Several BCL-2 family members have been implicated in hepatocarcinogenesis and in coupling apoptosis regulation and cell proliferation in unique ways $[8,9]$. 
BCL-2-related ovarian killer (BOK) is a BCL-2 family member with a function difficult to elucidate [10]. Early studies proposed that BOK may act as a BAX-like protein, based on sequence homology and since its over-expression induced cell death $[11,12]$. To date, functional studies on mammalian forms of BOK have largely been restricted to over-expression systems. Interestingly, and in contrast to BAX and BAK, BOK localizes preferentially to the membranes of the endoplasmic reticulum (ER) and the Golgi apparatus, but only weakly to mitochondria. Furthermore, we and others $[13,14]$ have shown that significant amounts of BOK are also present in the nucleus of mouse and human cells, including primary mouse hepatocytes and mouse embryo fibroblasts [15], as well as human non-small cell lung cancer cells [16]. ER-localization of BOK is supported by its interaction with inositol-3-phosphate receptors (IP3R) [17] and by its effect on $\mathrm{Ca}^{2+}$ homeostasis in neurons [18]. BOK was recently described to be rapidly turned over by the ubiquitin/proteasome pathway $[19,20]$ and to act as a non-canonical effector of intrinsic apoptosis regulated by

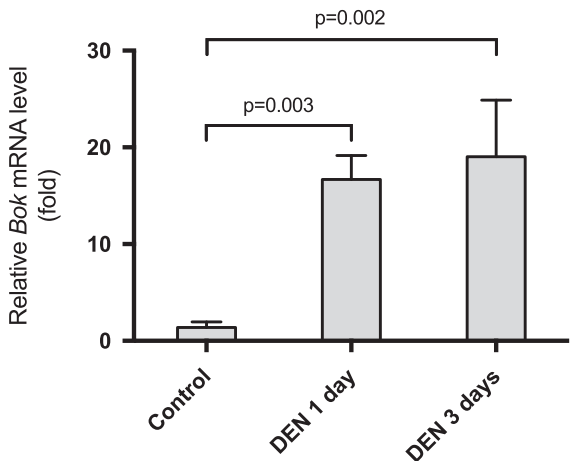

C
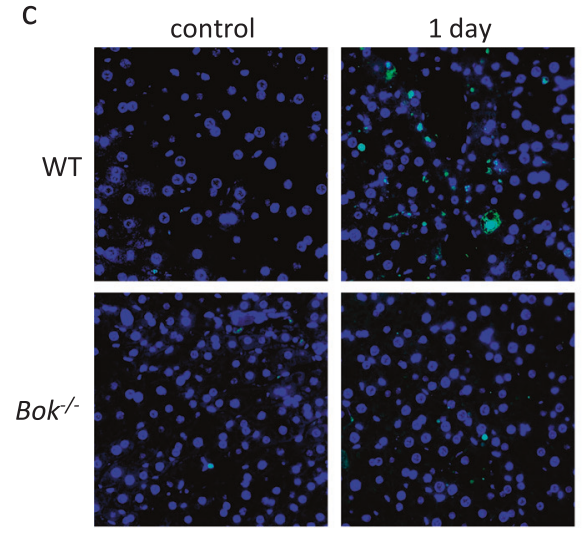

DAPI/TUNEL

e

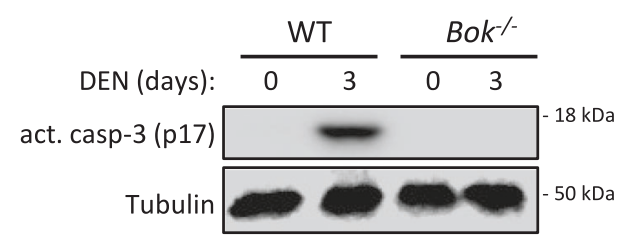

$b$

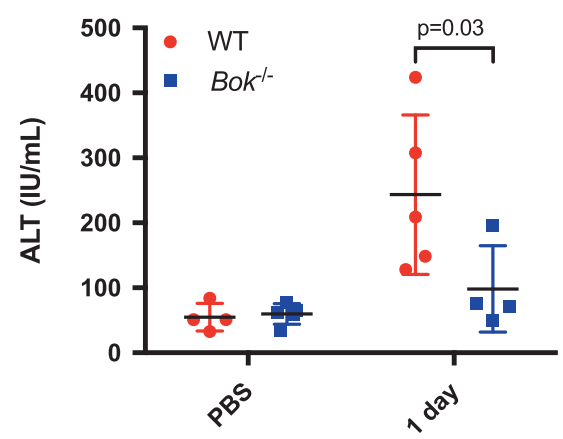

d
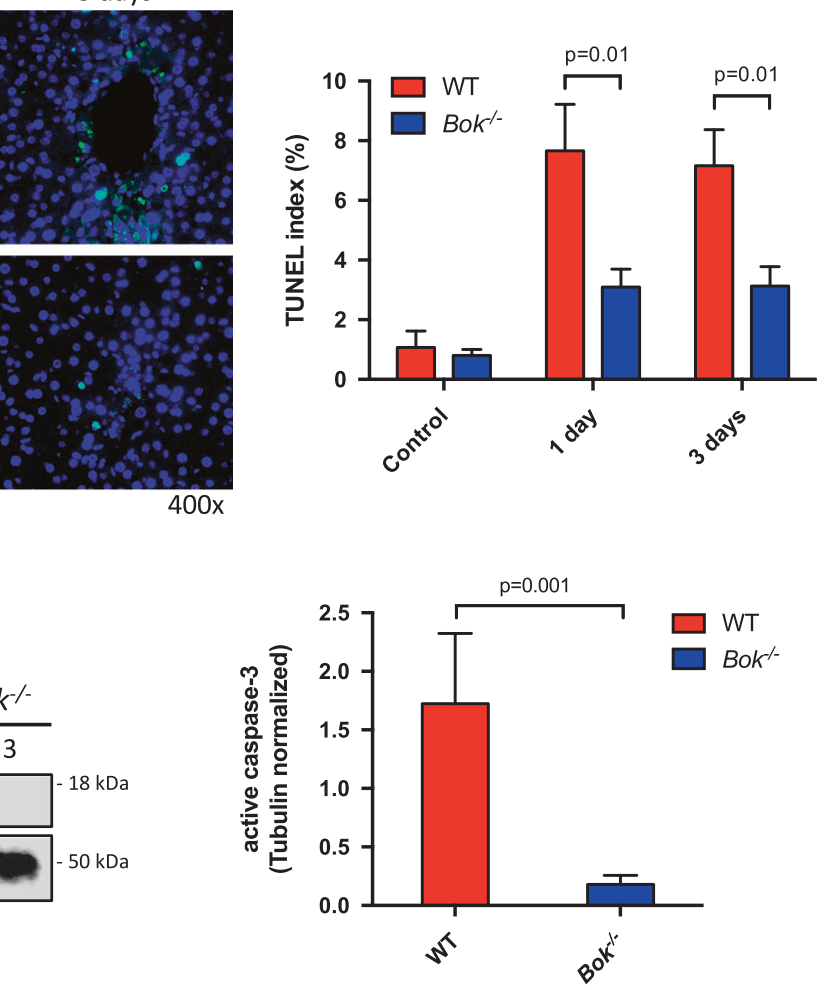

staining and $\mathbf{d}$ quantification of TUNEL-positive cells in livers from WT and $B^{-1 /}$ animals treated with DEN $(100 \mathrm{mg} / \mathrm{kg} \mathrm{BW})$. Values represent the mean $\pm \mathrm{SD}$ ( $n=3$ mice per group). e Quantitative western blot analysis using near-infrared fluorescence of activated caspase- 3 in liver lysates from WT and $B o k^{--}$animals 3 days after DEN $(100 \mathrm{mg} / \mathrm{kg})$ injection. Values represent the mean $\pm \mathrm{SD}$ ( $n=3$ mice per group) 
ER-associated degradation [19]. Whereas no overt spontaneous phenotype was seen in three independently derived Bok-deficient mouse strains [19, 21, 22], indirect indication for a physiological pro-apoptotic role of BOK was derived from analysis of $\mathrm{Bok}^{-1-} \mathrm{Bax}^{-/-}$females, which have an abnormally increased number of oocytes [23] and from a further, modest increase in lymphocyte numbers in a $\mathrm{Bax}^{-1-}$ $B a k^{-/}$hematopoietic system upon additional loss of Bok [24, 25]. Interestingly, $\mathrm{BO} K$ was identified in a genomic region that is relatively frequently deleted in human cancers [26]. Loss of Bok did, however, not affect the outcome of $E \mu$-myc transgene-induced preB-/B-cell lymphoma in the mouse [21]. The same study also showed that endogenous BOK levels are very low in lymphocytes, whereas generally BOK is widely expressed, with readily detectable protein expression levels in most tissues, particularly in reproductive organs, brain, and gastrointestinal tract, including liver $[15,21]$. Of note, there is no indication for increased deletion of the $B O K$ gene in human $\mathrm{HCC}$ according to The Cancer Genome Atlas (TCGA) database. Overall, the pathophysiological role of BOK remains elusive.

Here, we show that DEN treatment of mice results in an increased BOK expression in the liver and that BOK contributes to DEN-induced acute hepatocellular apoptosis. Induction of CHOP, PUMA, and BIM by DEN was decreased in $\mathrm{Bok}^{-/}$mice, as was the oligomerization of BAX, supporting a pro-apoptotic role of BOK upstream of mitochondria. As a consequence of reduced liver damage and resulting compensatory proliferation in an inflammatory environment, the incidence of HCC was significantly reduced in $\mathrm{Bok}^{-/}$mice compared to WT controls. Surprisingly, loss of BOK also resulted in smaller tumors, which correlated with reduced cellular proliferation of HCC both in vivo and in vitro, indicating that BOK does not only contribute to initial hepatocyte cell death but also affects cell cycle progression during hepatocarcinogenesis. Altogether, these data show that BOK plays a previously unrecognized role in the pathogenesis of liver disease.

\section{Results}

\section{BOK contributes to chemical-induced acute liver damage and hepatocyte apoptosis}

DEN is a potent alkylating agent inducing DNA damage and hepatocellular cell death upon conversion into alkyldiazohydroxide by intrahepatocellular cytochrome $\mathrm{P} 450$ [27]. In order to evaluate if DEN affects BOK expression levels we treated adult WT animals with DEN $(100 \mathrm{mg} / \mathrm{kg}$ BW). We observed that DEN promoted a strong upregulation (16-fold and 19-fold after 1 and 3 days, respectively) of
Bok mRNA in WT livers (Fig. 1a), indicating that Bok was transcriptionally induced. Bok induction was at least partially dependent on c-Jun $\mathrm{N}$-terminal kinase (JNK) as it was significantly reduced by D-JNKI1 inhibitor at early time points (1 day), whereas Bok levels were not affected upon loss of p53 (Supplementary Fig. S1). Importantly, BOK protein levels were also significantly increased after DEN challenge compared to controls (Fig. 2a). To test a potential pro-apoptotic role of BOK we compared DEN-induced acute liver damage in WT and $B o k^{-/}$animals. As shown in Fig. 1b, serum ALT levels were lower in $B o k^{-/}$animals 1 day after DEN exposure when compared to WT controls. TUNEL staining revealed less hepatocyte cell death in $\mathrm{Bok}^{-1-}$ mice (Fig. 1c and d). Proteolytic processing of procaspase- 3 into its active form was detected in livers from treated WT mice but was reduced in $B o k^{-/}$mice (Fig. 1e) indicating that $\mathrm{Bok}^{-/-}$animals were partially protected against DEN-induced liver damage. Of note, $\mathrm{CHOP}$ and the pro-apoptotic BH3-only proteins PUMA and BIM were strongly induced by DEN in WT livers, but clearly less so in livers of $\mathrm{Bok}^{-/}$mice (Fig. $2 \mathrm{~b}$ and $\mathrm{c}$ and Supplementary Fig. S2a). Taken together, these data indicate that DEN treatment induces BOK expression and that BOK contributes to DEN-mediated hepatocellular apoptosis upstream of CHOP, PUMA, and BIM. In support of a pro-apoptotic role of BOK upstream of mitochondrial permeabilization, we detected less activated BAX, as assessed by its oligomerization status, in livers from DEN-treated $\mathrm{Bok}^{-/-}$mice compared to WT controls (Supplementary Fig. S2b).

\section{$\mathrm{Bok}^{-/}$mice are partially protected from chemical- induced hepatocarcinogenesis}

DEN is a widely accepted agent to induce hepatocarcinomas in mice [3]. Acute cell death triggered by DEN promotes an inflammatory response that further stimulates tumor development [5]. We observed that $\mathrm{Bok}^{-/-}$animals presented significantly reduced mRNA levels of the proinflammatory cytokines TNF $\alpha$ and IL-6 in their livers compared to WT controls after short-term exposure to DEN, and that leukocyte infiltration, which became evident at day 3 of treatment, seemed to correlate with the degree of liver damage (Supplementary Fig. S3). We also noted that hepatocyte proliferation was decreased in $\mathrm{Bok}^{-/}$livers compared to WT controls 10 days after DEN treatment (Supplementary Fig. S4). Considering this, we sought to investigate how loss of BOK would affect DEN-induced hepatocarcinogenesis. Fifteen-day-old male WT and $\mathrm{Bok}^{-1-}$ mice were injected with a single dose of DEN $(25 \mathrm{mg} / \mathrm{kg}$ $\mathrm{BW}$; a dose that also induced BOK and BOK-dependent liver damage in adult WT mice, see Supplementary Fig. S5). At the endpoint of 9 months, macroscopic tumor 
a

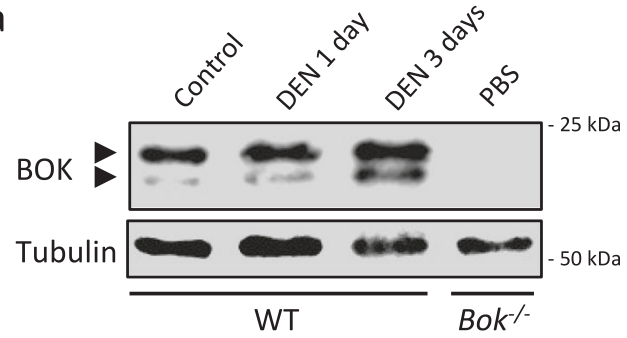

b

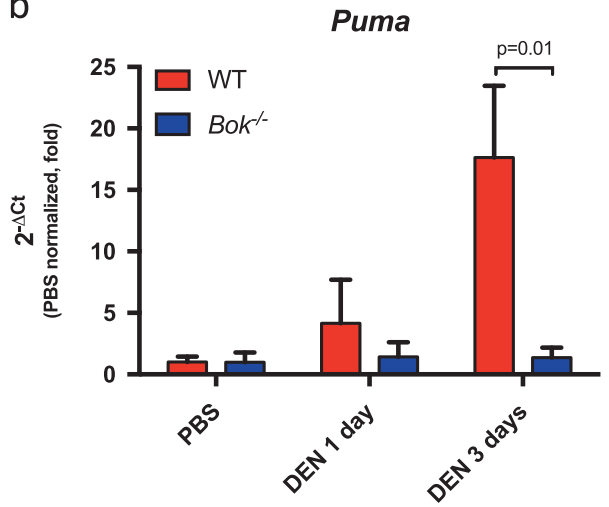

C

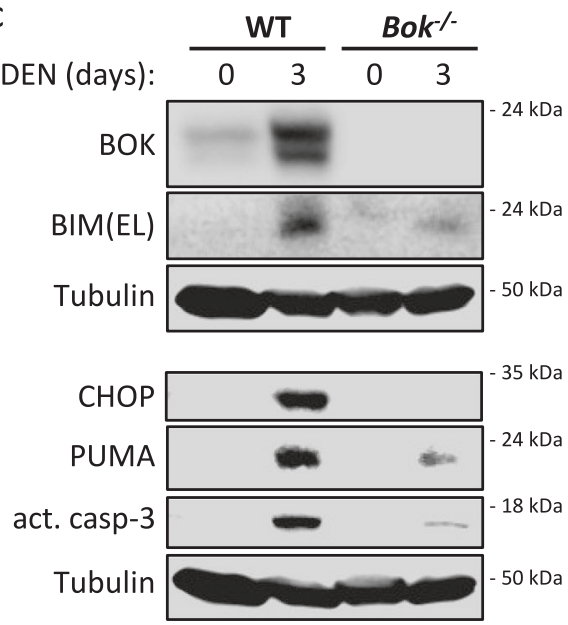

Fig. 2 BOK protein is increased in response to DEN and promotes induction of CHOP, BIM and PUMA. a Quantitative western blot analysis showing increase in BOK protein levels in WT animals treated with DEN $(100 \mathrm{mg} / \mathrm{kg})$. Lower band of BOK is due to alternative START codon [20]. Values represent mean $\pm \mathrm{SD}(n=3-6$ per group). Statistical analysis was performed by one-way ANOVA followed by a Tukey post-test analysis. b Induction of Bim and Puma

development was observed in both genotypes (Fig. 3a). However, $B o k^{-/}$animals presented significantly (three times) fewer tumors than WT controls (Fig. 3b). Interestingly, a reduced average tumor size was also observed in $B o k^{-/}$animals (Fig. 3c). Blinded histopathological evaluation confirmed that the prevalence of histologically confirmed HCC is significantly reduced in $\mathrm{Bok}^{-/-}$mice (Fig. 3d)
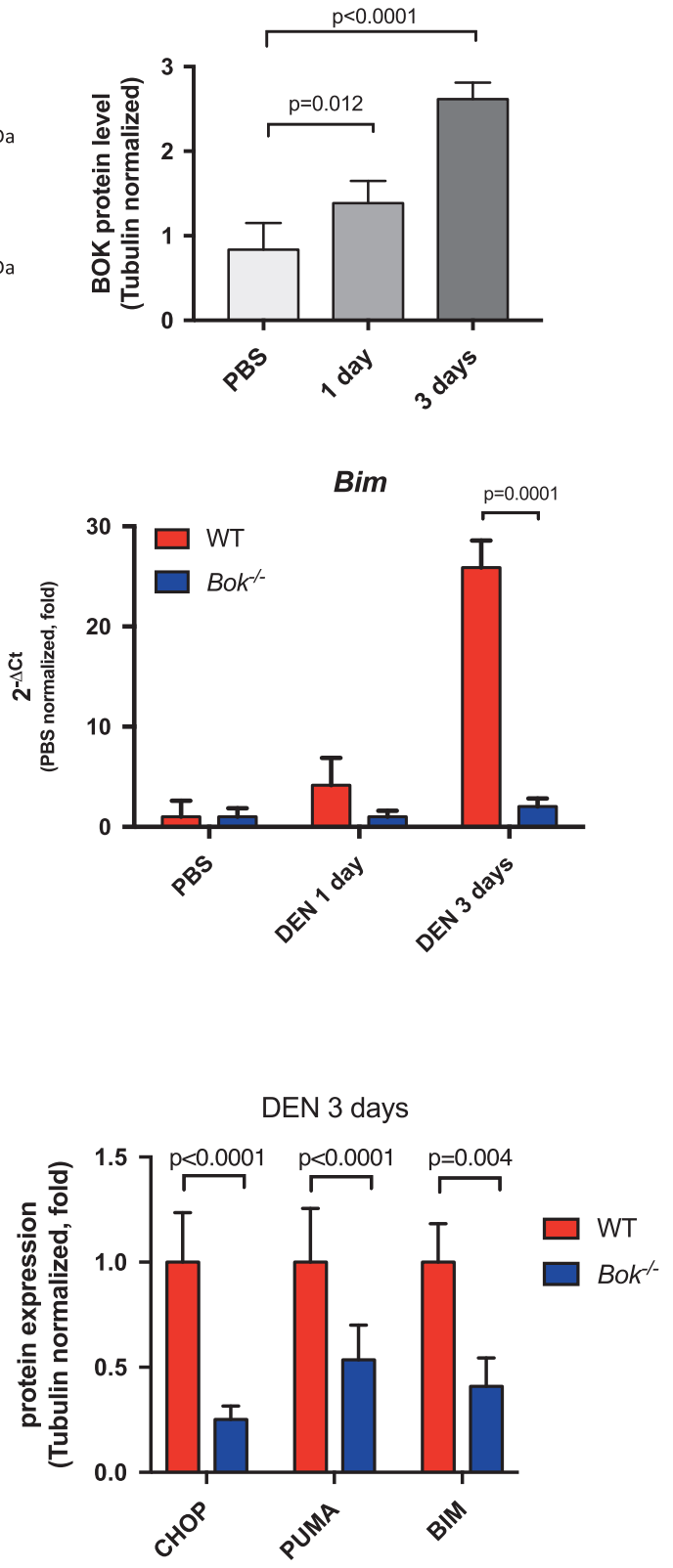

mRNA by DEN $(100 \mathrm{mg} / \mathrm{kg})$ is decreased in livers of $\mathrm{Bok}^{-/-}$mice. Gapdh served as reference gene. Values are normalized to PBS controls and represent the mean $\pm \mathrm{SD}$ ( $n=3$ mice per group). c Representative western blot data of liver lysates from DEN $(100 \mathrm{mg} / \mathrm{kg})$ treated WT and $\mathrm{Bok}^{-/}$mice and quantification using near-infrared fluorescence. Values represent the mean $\pm \mathrm{SD}$ ( $n=6$ mice per group)

and that $B o k^{-/}$animals present a lower incidence of inflammation, ballooning and steatohepatitis, and less steatosis (Fig. 3e and f). Neither WT nor Bok $k^{-/}$tumors or surrounding liver tissue showed increased signs of fibrosis (Supplementary Fig. S6). Taken together, these data indicate that BOK contributes to chemical-induced hepatocarcinogenesis. 
a

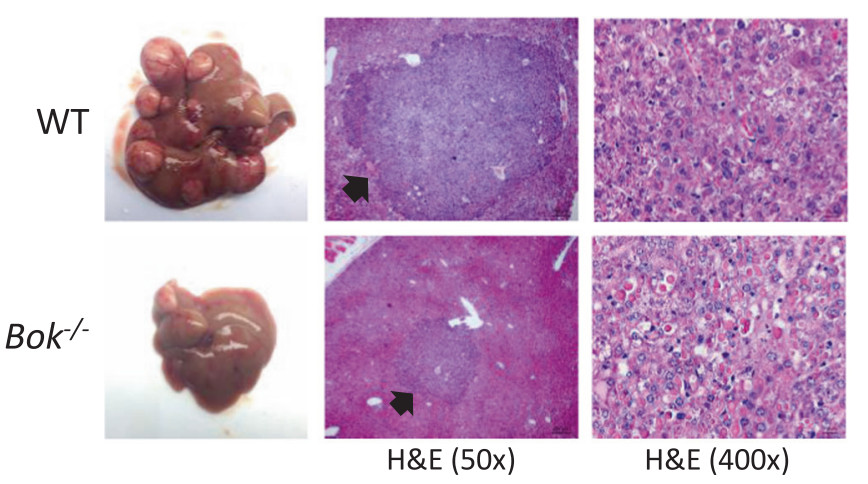

e

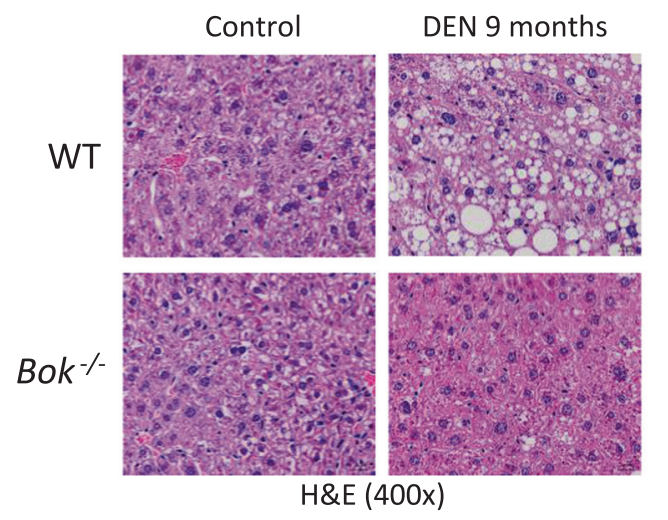

Histopathological Examination

\begin{tabular}{lcc}
\hline & WT & Bok $^{-/}$ \\
\hline number of animals & 10 & 10 \\
inflammation & $6 / 10$ & $0 / 10$ \\
ballooning & $6 / 10$ & $1 / 10$ \\
steatohepatitis & $6 / 10$ & $0 / 10$ \\
\hline
\end{tabular}

b

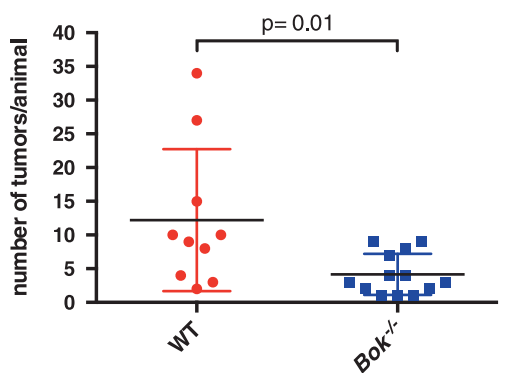

C
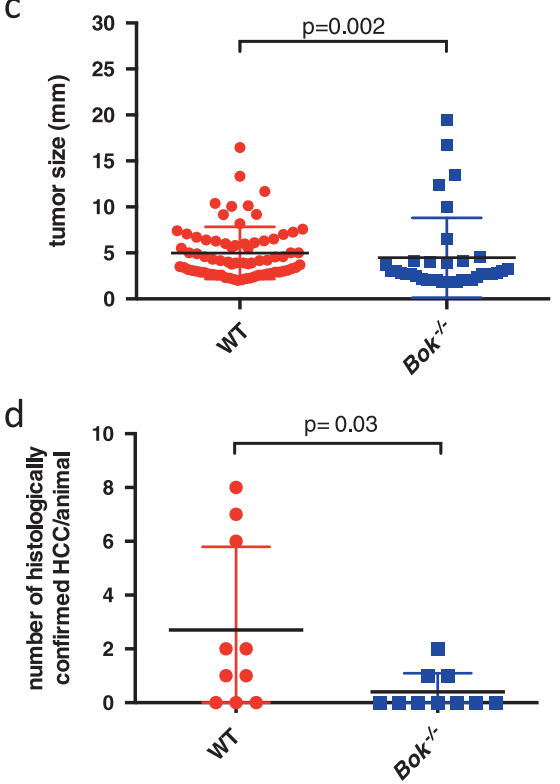

f

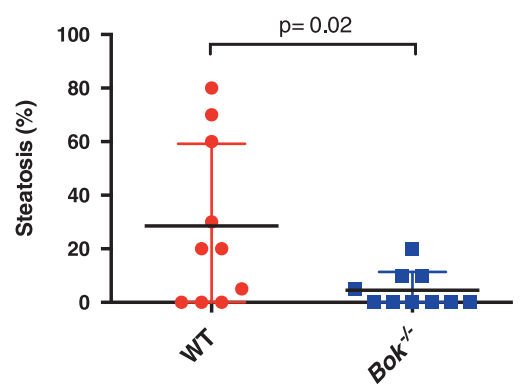

Fig. 3 BOK promotes chemical-induced hepatocarcinogenesis. a Gross liver tumor morphology and corresponding representative H\&Estained tumors in WT and $B o k^{-/}$animals 9 months after DEN treatment $(25 \mathrm{mg} / \mathrm{kg} \mathrm{BW})$. b Quantification of liver tumors in WT and $B o k^{-/}$ animals. Values represent the mean $\pm \mathrm{SD}$ (WT $n=10 ; B o k^{-/} n=13$ ). c Average tumor size per group (diameter by caliper). d Quantification of histologically confirmed HCC. Values represent the mean \pm SD ( $n$

\section{BOK deficiency limits cell proliferation}

Some BCL-2 family members are known to influence cell proliferation in addition to cell survival [28]. Bok ${ }^{-/}$animals presented not only fewer, but also smaller tumors than WT controls. Considering this, we compared the proliferative rate in liver tumors from WT and $B o k^{-/}$animals 9 months
$=10$ per group; blindly evaluated and randomly selected). e H\&Estained sections of livers 9 months after DEN injection. Histopathological examination revealed that $B o k^{-/}$animals are less prone to inflammation, ballooning, and steatohepatitis and $\mathbf{f}$ show less steatosis in non-tumor areas. Values represent the mean $\pm \mathrm{SD}(n=10$ per group; blindly evaluated and randomly selected)

after DEN treatment. Immunohistochemical quantification of the proliferation marker Ki-67 showed that tumors from $B o k^{-/}$animals presented three times fewer Ki-67 positive cells than tumors from WT controls (Fig. $4 \mathrm{a}$ and b). To evaluate if BOK deficiency could directly affect cell proliferation in vitro, we compared proliferation rates of immortalized human hepatocytes (IHH) and human HCC 
a

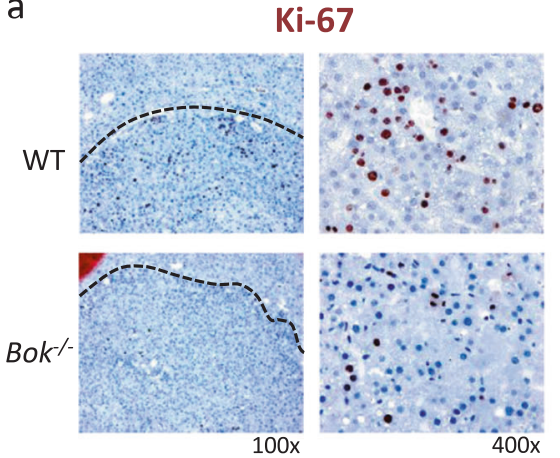

C

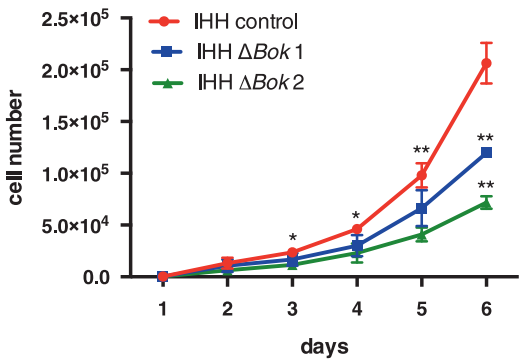

d

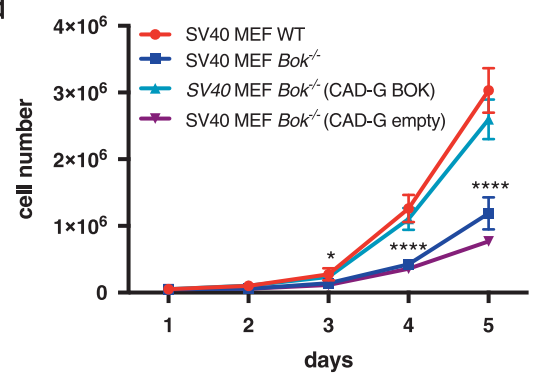

e

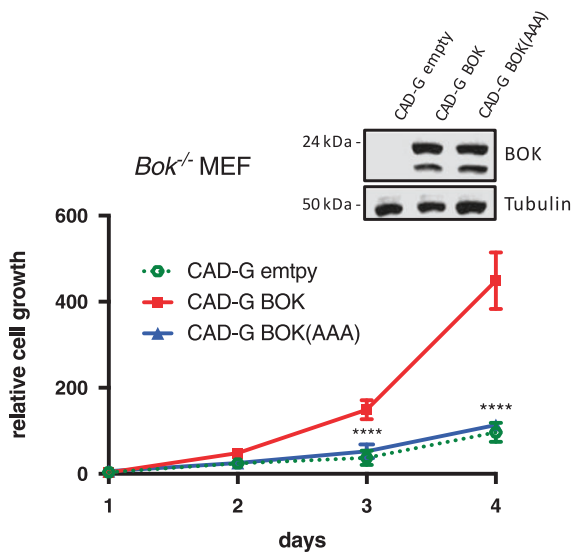

b
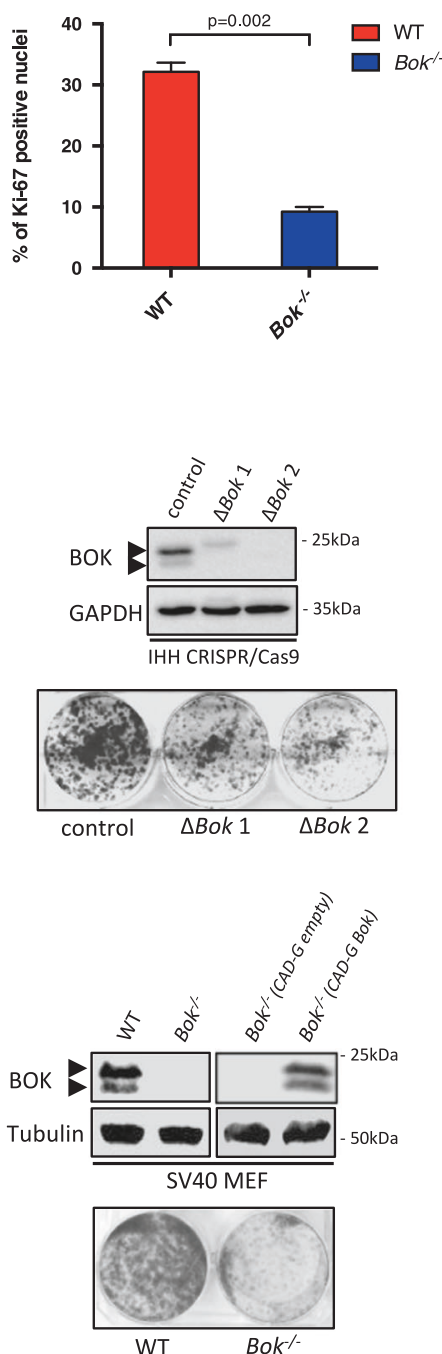

f

f $B$ Bok $/-M E F$

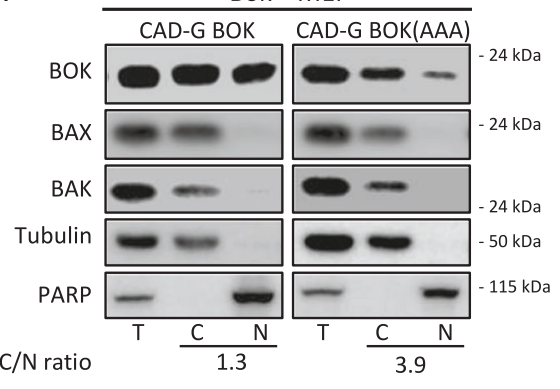

Fig. 4 Loss of BOK affects cellular proliferation. a Immunohistochemistry showing Ki-67 staining in HCC tumors from WT and $B o k^{-/-}$animals. b Quantification of Ki-67 positive cells in HCC tumors from WT and $B o k^{-/}$mice. Values represent the mean \pm SD ( $n=3$ mice per group). c Growth curves and colony formation assay of IHH subclones with CRISPR/Cas9-mediated gene disruption of BOK. d Growth curves and colony formation assay of SV40 MEF derived from three different WT and $B o k^{-/}$embryos, each. Stable re-expression of BOK in Bok $k^{-/}$SV40 MEF rescues the growth defect. e Stable re-expression of a BOK mutant, BOK(AAA), in which the predicted NES sequence within the BH3 domain has been mutated (L72A,R73A,L74A), fails to rescue the growth defect in $B o k^{-/-}$SV40 MEF. Values represent the mean \pm SD $(n=3)$. f BOK(AAA) accumulates in the cytoplasm compared to wildtype BOK. $T$ total, $C$ cytoplasmic fraction, $N$ nuclear fraction. * $p<0.05$, ** $p<0.01$, *** $p<0.005$, $* * * * p<0.001$ 
a
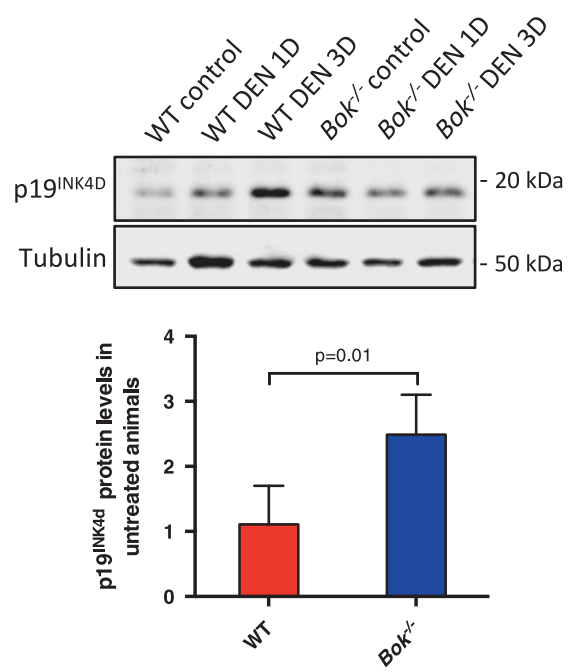

b

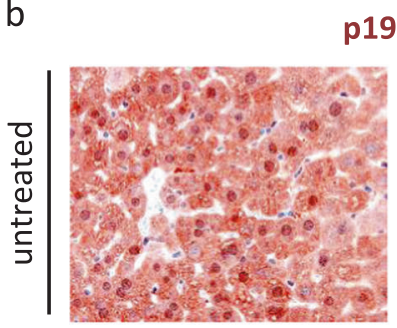

WT

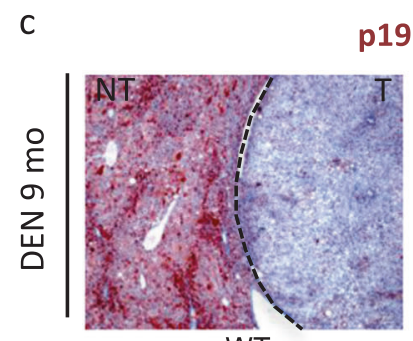

WT

19INK4d

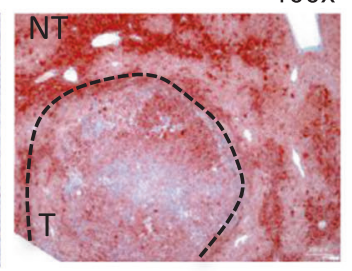

$\mathrm{Bok}^{-/-}$

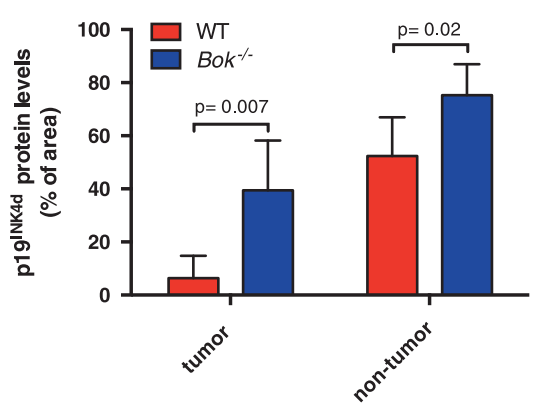

Fig. 5 Loss of BOK induces $\mathrm{p} 19^{\mathrm{INK} 4 \mathrm{~d}}$ and $\mathrm{p} 21^{\mathrm{cip} 1}$ expression. a Quantitative western blot analysis of $\mathrm{p} 19^{\mathrm{INK} 4 \mathrm{~d}}$ expression using nearinfrared fluorescence of liver extracts from WT and $B o k^{-/}$animals treated with DEN $(100 \mathrm{mg} / \mathrm{kg} \mathrm{BW})$. Values represent the mean \pm SD ( $n=4$ mice per group). b Immunohistochemistry of liver sections showing cytoplasmic and nuclear localization of $\mathrm{p} 19^{\mathrm{INK} 4 \mathrm{~d}}$ in untreated WT animals and predominantly nuclear localization in $\mathrm{Bok}^{-/}$livers. c Immunohistochemistry of liver sections indicating $\mathrm{p} 19^{\text {INK4d }}$ staining (red) in tumors from WT and $B o k^{-/}$animals. Counterstain was performed with Mayer's Hematoxilin. d Quantitative western blot analysis d
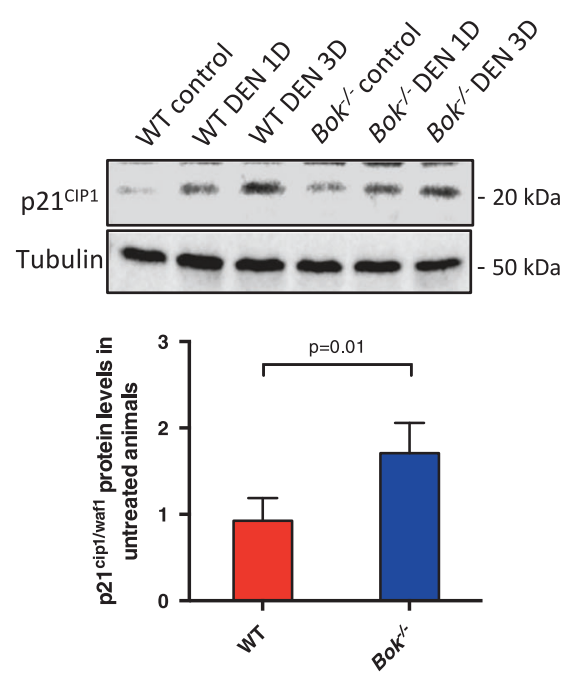

e

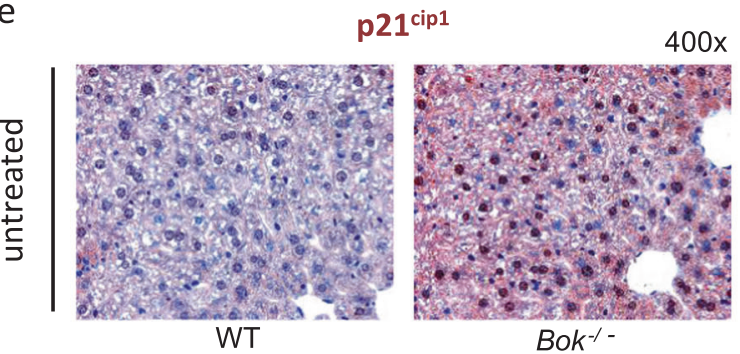

f

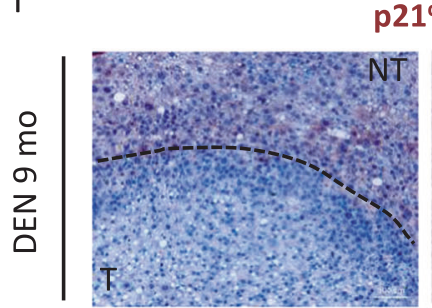

WT $21^{\text {cip1 }}$

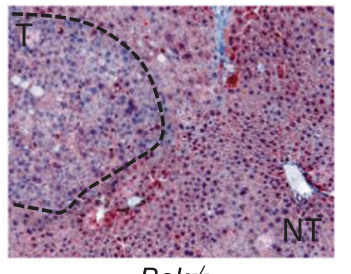

$\mathrm{Bok}^{-1-}$

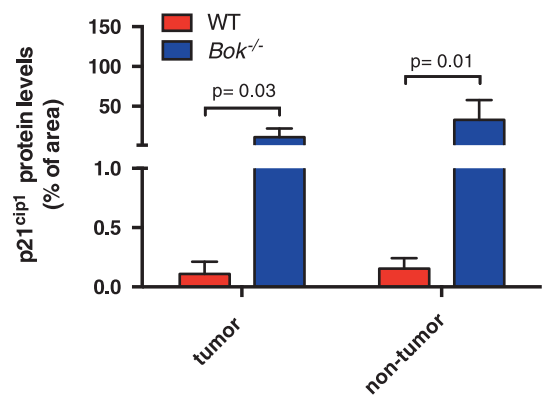

using near-infrared fluorescence of $\mathrm{p} 21^{\mathrm{cip} 1}$ expression of liver extracts from WT and $B o k^{-/}$animals treated with DEN (100 mg/kg BW). Values represent the mean $\pm \mathrm{SD}$ ( $n=4$ mice per group). e Immunohistochemistry of liver sections showing negative staining for $\mathrm{p} 21^{\text {cip1 }}$ in untreated WT animals and predominantly nuclear localization in $\mathrm{Bok}^{-/}$mice (red). f Immunohistochemistry of liver sections indicating p2 $1^{\text {cip } 1}$ negative staining in tumors from WT mice and positive staining for $B o k^{-/}$tumors (red). $T$ tumor area, $N T$ non-tumor area. At least two tumors/animal and 3-4 animals per genotype were used for quantifications in (c) and (f) 


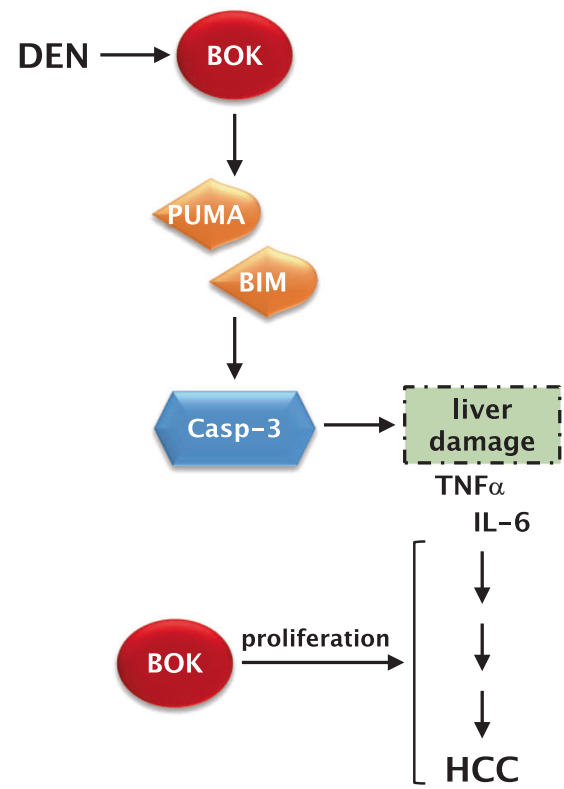

Fig. 6 Schematic model of how BOK contributes to DEN-induced HCC. BOK levels in the liver are increased in the short-term response to DEN and BOK contributes to liver damage upstream of BIM and PUMA induction. As a consequence of reduced cell death, associated inflammation and compensatory proliferation, $\mathrm{Bok}^{-/-}$mice develop fewer HCC tumors in the long term. Additionally, BOK has a likely cell death-independent function of positively modulating cellular proliferation of $\mathrm{HCC}$ cells, resulting in smaller tumors in $\mathrm{Bok}^{-/-}$mice

cell lines upon downregulation of $B O K$. As shown in Fig. 4c (and Supplementary Fig. S7), IHH cells and HepG2 human hepatocarcinoma cells with CRISPR/Cas9-mediated $B O K$ disruption, or the HCC cell line HLE upon shRNAmediated $B O K$ downregulation, proliferated significantly slower than controls. Growth curves and colony formation assays of immortalized mouse embryo fibroblasts (SV40 MEF) isolated from WT and $B o k^{-/}$mice further confirmed that loss of BOK can result in significantly slower proliferation (Fig. 4d). Importantly, re-expression of BOK in $\mathrm{Bok}^{-/}$MEF fully rescued this proliferation defect, proving that it is a BOK-specific effect (Fig. 4d). However, reexpression of a BOK mutant, BOK(L72A,R73A,L74A), in which the reported nuclear export signal (NES) [13] was destroyed, failed to rescue the growth defect in $\mathrm{Bok}^{-/-} \mathrm{MEF}$ (Fig. 4e). The same mutant also showed a reduced localization in purified nuclear fractions and consequently accumulated in the cytoplasm (Fig. 4f). Given that the NES of BOK is situated within its BH3-domain, these data imply that $\mathrm{BOK}$ requires either its $\mathrm{BH} 3$ domain and/or a nuclear localization to drive proliferation. Nuclear localization of BOK was confirmed in HLE cells and, interestingly, cytoplasmic-to-nuclear ratio of BOK likewise increased upon knockdown of BOK (Supplementary Fig. S7g). Loss of BOK also negatively affected cell growth of non- transformed bone marrow-derived mast cells (Supplementary Fig. S8). Taken together, these data indicate that BOK plays a role in controlling cellular proliferation in vitro and in vivo.

\section{Loss of BOK promotes induction of cyclin kinase inhibitors $\mathrm{p} 19^{\text {ink4d }}$ and $\mathrm{p} 21^{\text {cip1 }}$}

To gain further insight into the role of BOK in cell proliferation, expression profiling of 88 cell cycle related genes was performed with IHH and two human HCC lines, in which $B O K$ was deleted or downregulated. Only few genes showed consistent changes in expression levels among the three different cell lines. The genes upregulated in $B O K$-deficient cells were linked to cell cycle arrest and DNA damage response, including cyclin kinase inhibitor $C D K N 2 D$ (p19 ${ }^{\text {INK4d }}$ ), BCL-2, TP53, RPA3, GADD45A-6, $C D K 5$, whereas only $C C N A 2$, encoding for cyclin A2, was consistently downregulated (Supplementary Fig. S9). To better understand the impact of $B O K$ deletion on $C D K N 2 D$ expression, we evaluated $\mathrm{p} 19^{\mathrm{INK} 4 \mathrm{~d}}$ protein expression in livers from short-term DEN treated WT and $\mathrm{Bok}^{-/}$animals. Of note, p19 ${ }^{\text {INK4d }}$ steady-state protein levels were, on average, two times higher in livers from $\mathrm{Bok}^{-/}$animals compared to WT controls (Fig. 5a). Whereas p19 $9^{\mathrm{INK} 4 \mathrm{~d}}$ levels increased upon DEN treatment in WT livers, they remained unchanged in $B o k^{-/}$livers. Interestingly, $\mathrm{p} 19^{\mathrm{INK} 4 \mathrm{~d}}$ was differentially distributed in hepatocytes of WT and $\mathrm{Bok}^{-/}$animals. Whereas p19 ${ }^{\mathrm{INK} 4 \mathrm{~d}}$ was localized both in the cytoplasm and in the nucleus of WT hepatocytes, it was found predominantly in the nucleus of $\mathrm{Bok}^{-1}$ hepatocytes (Fig. 5b). In the tumors of DEN-treated WT animals $\mathrm{p} 19^{\text {INK4d }}$ expression was reduced compared to adjacent 'healthy' liver tissue, whereas the tumors of $\mathrm{Bok}^{-1-}$ animals expressed readily detectable levels of p19 $9^{\mathrm{INK} 4 \mathrm{~d}}$ in both HCC tumors and surrounding 'healthy' liver tissue (Fig. 5c). We also observed that BOK repression affected expression of another cyclin kinase inhibitor, p21 $1^{\text {cip } 1}$ (Fig. 5d). p2 $1^{\text {cip1 }}$ was strongly expressed and mainly localized in the nuclei of hepatocytes from $\mathrm{Bok}^{-/-}$mice, while it was hardly detectable in WT hepatocytes (Fig. 5e). In addition, tumors and adjacent tissue from $\mathrm{Bok}^{-/}$animals were positive for $\mathrm{p} 21^{\mathrm{cip} 1}$, whereas tumors from WT animals were consistently negative (Fig. 5f). Using isogenic HCT-116 colorectal carcinoma cells proficient or deficient for $\mathrm{p} 53$ or $\mathrm{p} 21$, respectively, we observed that the growth defect inflicted upon downregulation of $B O K$ was dependent on p21 and p53 (Supplementary Fig. S10). Taken together, these data indicate that BOK depletion affects the expression of genes implicated in cell cycle arrest, and remarkably, impacts on the expression pattern of $\mathrm{p} 19^{\mathrm{INK} 4 \mathrm{~d}}$ and $\mathrm{p} 21^{\mathrm{cip} 1}$ in hepatocytes and HCC cells. 


\section{Discussion}

Despite its discovery 20 years ago the physiological and pathophysiological relevance of $\mathrm{BOK}$ remains largely unknown. BOK induces apoptosis when over-expressed and it shows best amino acid sequence homology to BAK and BAK. However, it is currently controversially discussed whether BOK is a genuine pro-apoptotic BCL-2 family member and whether it can induce intrinsic apoptosis independently of BAX/BAK [15, 18, 19, 22, 29-31]. What has emerged is that BOK is widely expressed and readily detectable at the endogenous protein level in most cell types, maybe with the exception of the hematopoietic system [21], and that in contrast to BAX and BAK, most of the cytoplasmic BOK localizes to the ER; furthermore, BOK is also prominently found in nuclear fractions [13-16].

BOK is consistently expressed throughout the gastrointestinal tract, with high levels in the liver [21]. Here we show that BOK is strongly induced at the mRNA and protein levels upon short-term treatment with DEN and, importantly, that BOK promotes DEN-induced liver damage and associated inflammation. Induction of Bok mRNA seems to be at least partially mediated by JNK, but independent of $\mathrm{p} 53$, which is in analogy to a report for the induction of Puma by DEN [8]. As shown by Das and colleagues using conditional Jnkl/2-deficient mice, the role of JNK is ambiguous, with different effects on HCC development in hepatocytes or non-parenchymal cells [32]. Our study was performed in a constitutive Bok-deficient strain, which limits the conclusions to some extents. Conditional deletion of Bok (i.e. hepatocyte-specific and/or nonparenchymal-specific deletion) will be necessary to demonstrate the contribution of BOK in hepatocytes or nonparenchymal cells, respectively, in the DEN model and, importantly, to address a possible role of liver resident (or recruited) leukocytes therein.

Our findings show that BOK contributes to chemicalinduced hepatocellular apoptosis (see Fig. 6 for a schematic model). In line with its localization at the ER and our previous observation that over-expressed $\mathrm{BOK}$ induces $\mathrm{BIM}$ and PUMA [15], we found that BOK acts upstream of CHOP, BIM, and PUMA induction in response to DEN. A connection between BOK and $\mathrm{CHOP}$ has been reported earlier, albeit in a different context [22]. Overall, these data support a pro-apoptotic role of BOK upstream of mitochondrial apoptotic events mediated by BAX/BAK, and this was further underlined by our finding that BAX oligomerization, which we used as a readout for its activation status, is reduced in livers of short-term DEN-treated $\mathrm{Bok}^{-/-}$mice compared to WT controls.

Reduction of apoptosis and, consequently, inflammation and compensatory hepatocellular proliferation is strongly associated with reduced HCC development [5-7]. In line with these observations, we report that at the endpoint of 9 months after DEN exposure $\mathrm{Bok}^{-/}$animals were partially protected from HCC development, displaying significantly reduced tumor numbers, as well as smaller tumors. Interestingly, $B O K$ was identified in a genomic region that undergoes relative frequent deletion in human cancers, making $B O K$ one of the most often deleted members among the pro-apoptotic BCL-2 family [26]. However, according to The Cancer Genome Atlas (TCGA) database, the human $B O K$ locus is rarely deleted in primary liver cancer. Likewise, $B O K$ mRNA levels do not seem to be decreased in human HCC based on publicly available databases. Information on the BOK protein status in human HCC specimens is currently missing. Nevertheless, we observed that established HCC in WT mice expressed comparable levels of BOK protein compared to healthy liver (data not shown). This apparent lack of selection pressure to lose BOK during liver cancerogenesis is in line with our finding that BOK promotes HCC. Our findings support other reports on proapoptotic BCL-2 proteins promoting HCC, such as PUMA [8] or BID [9]. Inversely, loss of anti-apoptotic MCL-1 in hepatocytes was shown to trigger spontaneous apoptosis and to promote development of HCC [33]. Along the same line, over-expression of BCL-2 was shown to inhibit SV40 large $\mathrm{T}$ antigen transgene-induced liver cancer development [34]. Interestingly, loss of Puma has also been implicated with decreased tumorigenesis in a radiation-induced thymic lymphoma model $[35,36]$. Collectively, these findings suggest that damage-induced cell death can promote tumour development by causing enhanced proliferation of progenitor cells, which due to their rapid proliferation may sustain oncogenic DNA lesions.

Following our observation that $\mathrm{Bok}^{-/}$mice also presented smaller tumors, we demonstrate that loss of BOK negatively affects cellular proliferation. Tumors from $\mathrm{Bok}^{-/}$animals proliferated slower than tumors form WT mice. In addition, two human HCC lines, IHH, MEF, and non-transformed mast cells proliferated significantly slower upon loss of BOK. This result points towards an important role of BOK that may be independent of its role in cell death regulation. Based on these findings that link BOK to the regulation of HCC proliferation, targeting BOK in established HCC expressing high levels of BOK may be beneficial in slowing tumor growth.

A nuclear localization of BOK has been reported by several groups and linked to proliferation in trophoblasts during early placentation [13, 14]. In support of this, we have previously shown that significant amounts of total $\mathrm{BOK}$ are found in purified nuclear fractions of MEF, mouse primary hepatocytes and in a panel of human non-small cell lung carcinoma cells lines, and that loss of BOK decreases cell growth in the latter $[15,16]$. Here we demonstrate that this is also true for $\mathrm{HCC}$ cells, in which loss of BOK 
resulted in reduced proliferative capacity in vitro and in vivo. Interestingly, downregulation of $B O K$ in HLE cells resulted also in an increased cytoplasmic-to-nuclear BOK ratio. It is therefore an interesting hypothesis to segregate a role of cytoplasmic BOK in cell death regulation from a putative role of nuclear BOK in proliferation. Importantly, reduction of BOK by RNA interference or gene editing by CRISPR/Cas9, resulted in induction of several genes implicated with cell cycle arrest: $B C L-2$, recognized as cell cycle regulator and able to inhibit liver carcinogenesis upon over-expression in mice [37]; $C D K 5$, which is essential for neuronal cell cycle arrest and differentiation [38]; and $\mathrm{p} 19^{\mathrm{INK} 4 \mathrm{~d}} \cdot \mathrm{p} 19^{\mathrm{INK} 4 \mathrm{~d}}$ was described to improve DNA repair, decrease apoptosis and increase neuronal survival in conditions of genotoxic stress [39]. Additionally, p19 $9^{\mathrm{INK} 4 \mathrm{~d}}$ is normally localized both in the nucleus and cytoplasm [40]. We confirmed this cellular distribution in livers of WT animals. Intriguingly, however, the expression of $\mathrm{p} 19^{\mathrm{INK} 4 \mathrm{~d}}$ in $B o k^{-/}$hepatocytes was predominantly nuclear, similar to the distribution pattern reported for cells treated with UV radiation [41]. We also show that $\mathrm{p} 19^{\mathrm{INK} 4 \mathrm{~d}}$ expression was strongly reduced in DEN-induced HCC tumor tissue of WT mice whereas it remained detectable in tumors of $\mathrm{Bok}^{-1-}$ animals. This result is in line with a previous report showing that $\mathrm{p} 19^{\mathrm{INK} 4 \mathrm{~d}}$ expression is frequently lost in HCC, actually proposing it as a new prognostic marker [42]. Like $\mathrm{p} 19^{\mathrm{INK} 4 \mathrm{~d}}, \mathrm{p} 21^{\text {cip } 1}$, another cyclin kinase inhibitor with a recognized role both in normal hepatocytes and in hepatocarcinogenesis [43, 44], was found to be upregulated in BOK-deficient tumors. We accordingly found that loss of the proliferative capacity in the absence of BOK depends on p21 and p53 in HCT-116 cells. Furthermore, we identified the previously reported NES sequence of BOK [13], which intriguingly is located within its BH3 domain, as crucial sequence to drive proliferation. In contrast to Bartholomeusz et al., however, we found that BOK with a mutated NES accumulates in the cytoplasm rather than in the nucleus. The underlying reason for this discrepancy is currently not clear and warrants further investigation. Taken together, our data indicate that $\mathrm{BOK}$ either requires its $\mathrm{BH} 3$ domain and/or a nuclear localization in order to affect cellular proliferation. Interestingly, $\mathrm{p} 21^{\mathrm{cip} 1}$ and $\mathrm{p} 19^{\mathrm{INK} 4 \mathrm{~d}}$ activation may also be involved in senescence induction, which is another well-described tumor suppressive mechanism through which pre-malignant senescent hepatocytes are subjected to immune cell-mediated clearance [4]. Even though mouse leukocytes express very low levels of BOK $[15,21]$, generation of a conditional Bok-deficient mouse model is necessary to address a specific role of BOK in immune cells in DEN-induced HCC.

In summary, we show that BOK is induced by DEN and that BOK contributes to DEN-induced hepatocellular apoptosis and subsequent hepatocarcinogenesis. Furthermore, loss of BOK results in reduced proliferation of HCC cells in vitro and in vivo, correlating with an upregulation of genes enrolled in cell cycle arrest with a recognized role in hepatocarcinogenesis. Considering this, it is reasonable to propose that strategies aiming to prevent $\mathrm{BOK}$ induction or activation during liver injury may have a favorable impact on HCC development and progression.

\section{Materials and methods}

\section{Reagents}

IMDM, RPMI 1640 medium, and DEN were purchased from Sigma-Aldrich (Buchs, CH). DMEM/GlutaMAX, penicillin/streptomycin, L-glutamine, and trypsin solution were purchased from Thermo Fisher Scientific. Fetal calf serum (FCS, Sera Pro, ultra-low endotoxin) was purchased from Pan Biotech (Aidenbach, DE).

\section{Mice and treatment}

$\mathrm{Bok}^{-/}$mice were generated on a C57BL/6 inbred genetic background as previously described [21] and were used along with corresponding age-matched and sex-matched WT animals. All mice were maintained in pathogen-free conditions with free access to food and water. Experiments were approved by the Animal Experimentation Review Board of the Canton of Bern, Switzerland (BE15/13). All mice received humane care according to the criteria outlined in the Guide for Care and Use of Laboratory Animals (National Institutes of Health publications 86-23, revised 1985). For DEN-induced HCC, DEN ( $25 \mathrm{mg} / \mathrm{kg}$ body weight) was injected intraperitoneally into 14 days old males. Mice were sacrificed after 9 months on the standard diet (Complete Food for Mice and Rats, No. 3432, Kliba Natag, Kaiseraugust, CH). Tumors in each liver lobe were counted and measured with a caliper. Tumor and non-tumor tissue was collected and quickly processed for histological, immunochemical, and biochemical analyses. Acute effects of DEN were studied in adult mice injected intraperitoneally with $100 \mathrm{mg} / \mathrm{kg}$ DEN and sacrificed after 1,3 , and 10 days, respectively.

\section{Alanine aminotransferase (ALT) measurement}

Serum values of ALT were measured using the ALT Enzymatic Assay according to the manufacturer's instructions (Bioo Scientific, Austin, TX, USA).

\section{Histology and histopathology}

Freshly dissected liver samples were fixed in $3.7 \%$ formaldehyde for $24 \mathrm{~h}$, embedded in paraffin and $4 \mu \mathrm{m}$ tissue 
sections stained with hematoxylin and eosin or processed for immunohistochemistry. Histopathological evaluation was performed blindly by a pathologist (M.M.).

\section{Immunoblotting}

Details on sample preparation and SDS-PAGE can be found in the Online Supplementary Material. Immunoprobing was performed with the following antibodies: mouse antitubulin (B-5-1-2; Sigma-Aldrich); rabbit anti-p21 (C-19; sc-397) and rabbit anti-CHOP (B-3) (Santa Cruz Biotechnologies); rabbit anti-cleaved caspase-3(D175) (5A1E) and rabbit anti-PUMA (\#7467) from Cell Signaling Technology; rat anti-BIM (3C5, Enzo Life Sciences); and rabbit anti-p19 INK4d (ab102842, Abcam). Rabbit monoclonal anti-BOK, RabMab BOK-1-5 [15]. IRDye ${ }^{\circledR} 800 \mathrm{CW}$ and $600 \mathrm{CW}$ near-infrared fluorochrome-conjugated secondary antibodies were purchased from LI-COR Biotechnology (Bad Homburg, DE). Quantitative western blot analysis was performed using an Odyssey Fc digital imaging system from LI-COR Biotechnology. Alternatively, horseradish peroxidase-coupled secondary antibodies (Jackson ImmunoResearch Europe Ltd.) were used and signals detected on an Odyssey Fc system by enhanced chemiluminescence (Luminata Forte, Merck Millipore). Data was quantified using Image Studio 3.1.4 software (LI-COR).

\section{Cytoplasmic/nuclear fractionation}

Cytoplasmic and nuclear fractions were prepared according to [45] with some modifications. Briefly $3.5 \times 10^{6}$ cells were incubated in $0.5 \mathrm{ml} \mathrm{F1}$ buffer $(20 \mathrm{mM}$ Tris $\mathrm{pH} 7.6,50$ $\mathrm{mM} \beta$-mercaptoethanol, $0.1 \mathrm{mM}$ EDTA, $2 \mathrm{mM} \mathrm{MgCl} 2$, plus protease inhibitor cocktail) for $2 \mathrm{~min}$ at RT and $10 \mathrm{~min}$ on ice. Fifty microliters of $10 \%$ NP-40 were added and cells lysed by passing $3 \times$ through a $21 \mathrm{G}$ needle. Lysate was centrifuged at $600 \times g$ for $5 \mathrm{~min}$ at $4{ }^{\circ} \mathrm{C}$ and supernatant collected as cytoplasmic (C) fraction. Pellet was washed $3 \times$ in F1 buffer containing 1\% NP-40 and processed as nuclear (N) fraction.

\section{Immunofluorescence and immunohistochemistry}

Immunostaining was performed after deparaffinization and rehydratation through graded alcohol. Antigen retrieval was performed in Dako Target Retrieval solution pH 6.0 (Dako, Baar, $\mathrm{CH}$ ) using an electric pressure cooker (2100 Retriever, Aptum, Southampton, UK). Immunofluorescence was performed with the following primary antibody incubated overnight at $4{ }^{\circ} \mathrm{C}$ : rabbit anti-Ki-67 (SP6, Thermo Fisher Scientific) diluted in Dako Real ${ }^{\mathrm{TM}}$ antibody diluent. Incubation with Alexa Fluor 488-conjugated IgG F(ab'2) secondary antibody (Thermo Fisher Scientific) was performed at RT for $1 \mathrm{~h}$. Nuclear DNA was counterstained with Prolong Gold antifade reagent containing DAPI (Thermo Fisher Scientific). Immunohistochemistry was performed with the following primary antibodies: rabbit anti-p21 (C19) (sc-397, Santa Cruz Biotechnologies), and rabbit antip19 INK4d (ab102842, Abcam). Staining was performed with Dako Envision ${ }^{\mathrm{TM}}$ System-HRP specific for rabbit primary antibodies following the manufacturer's instructions. Staining was evaluated by Image-Pro Plus software (Media Cybernetics) and the area was analyzed by the count and size tool with hue saturation intensity (HSI) mode.

Cell death was evaluated by TUNEL staining following the manufacturer's instructions (In Situ Cell Death Detection Kit, Fluorescein, Roche Diagnostics). Images were acquired using a Zeiss Observer Z.1 fluorescence microscope connected to a Axiocam 506 digital color camera and using the ZEN pro 2012 (blue edition) software (Zeiss, Feldbach, CH). The percentage of Ki-67 and TUNEL positive cells was determined by counting at least 900 nuclei per condition.

\section{RNA isolation and quantitative RT-PCR (qPCR)}

Total RNA was extracted from liver samples with SV total RNA isolation system (Promega, Wallisellen, $\mathrm{CH}$ ). One microgram of RNA was reverse-transcribed using oligo(dT) primer and M-MLV reverse transcriptase according to the manufacturer's instructions (Promega). qPCR reaction was performed using HOT FIREPol 'EvaGreen' qPCR Mix Plus (Solis Biodyne, Tartu, EST) on a Real-Time PCR detection system (CFX Connect ${ }^{\mathrm{TM}}$, Bio-Rad). Mouse Hprt or Gapdh mRNA were used as reference genes. For primer sequences see Supplementary Table S1.

\section{Statistical analysis}

Statistical analysis was performed using Prism 6 software (GraphPad Software, Inc., La Jolla, CA, USA). Data are presented as means \pm standard deviation (SD). Unless otherwise stated, statistical significance was calculated using the Student $t$-test or using a non-parametric Mann-Whitney test for samples not following normal distribution with homogenous variances. $P<0.05$ was considered significant.

Acknowledgements We are grateful to Dr. Fabio Passetti (Rio de Janeiro, BR) for TCGA database analysis, and Drs. T. Brunner (Konstanz, DE), C. Borner (Freiburg, DE), M. Tschan, M. Medova, and H.-U. Simon (all Bern, $\mathrm{CH}$ ) for reagents. This work has been supported by grants from the Swiss Cancer League (No. KFS-301408-2012; to T.K.); Swiss National Science Foundation (SNSF, grant no. $310030 \mathrm{E}-150805 / 1$, part of FOR-2036, and 31003A_173006; to TK) and the Austrian Science Fund (FWF, grant no. I1298 \& W1101). Y.F.M., G.L., and S.W. were Ph.D. students of the Graduate School of Cellular and Biomedical Sciences of the University of Bern. V.S. is 
Ph.D. student of the Molecular Cell Biology and Oncology (MCBO) of the Medical University Innsbruck. Images were acquired on equipment supported by the Microscopy Imaging Centre of the University of Bern.

Author contributions Study concept and design (T.R., T.K.); acquisition of data (T.R., Y.F., D.B., S.W., V.S., Z.H.); analysis and interpretation of data (T.R., T.K., Y.F., D.B., M.M., V.S., Z.H.); drafting the manuscript (T.R., T.K.); critical revision of the manuscript for important intellectual content (D.S., G.L., A.V.); obtaining funding (T.K.); and study supervision (T.K.).

\section{Compliance with ethical standards}

Conflict of interests The authors declare that they have no competing interests.

Open Access This article is licensed under a Creative Commons Attribution-NonCommercial-ShareAlike 4.0 International License, which permits any non-commercial use, sharing, adaptation, distribution and reproduction in any medium or format, as long as you give appropriate credit to the original author(s) and the source, provide a link to the Creative Commons license, and indicate if changes were made. If you remix, transform, or build upon this article or a part thereof, you must distribute your contributions under the same license as the original. The images or other third party material in this article are included in the article's Creative Commons license, unless indicated otherwise in a credit line to the material. If material is not included in the article's Creative Commons license and your intended use is not permitted by statutory regulation or exceeds the permitted use, you will need to obtain permission directly from the copyright holder. To view a copy of this license, visit http://creativecommons. org/licenses/by-nc-sa/4.0/.

\section{References}

1. Farazi PA, DePinho RA. Hepatocellular carcinoma pathogenesis: from genes to environment. Nat Rev Cancer 2006;6:674-87.

2. Sherman M. Hepatocellular carcinoma: epidemiology, risk factors, and screening. Semin Liver Dis 2005;25:143-54.

3. Newell P, Villanueva A, Friedman SL, Koike K, Llovet JM. Experimental models of hepatocellular carcinoma. J Hepatol 2008;48:858-79.

4. Kang TW, Yevsa T, Woller N, Hoenicke L, Wuestefeld T, Dauch $\mathrm{D}$, et al. Senescence surveillance of pre-malignant hepatocytes limits liver cancer development. Nature 2011;479:547-51.

5. Maeda S, Kamata H, Luo JL, Leffert H, Karin M. IKKbeta couples hepatocyte death to cytokine-driven compensatory proliferation that promotes chemical hepatocarcinogenesis. Cell 2005;121:977-90.

6. Kuraishy A, Karin M, Grivennikov SI. Tumor promotion via injury- and death-induced inflammation. Immunity 2011;35:467-77.

7. Schattenberg JM, Schuchmann M, Galle PR, Cell death and hepatocarcinogenesis: dysregulation of apoptosis signaling pathways. J Gastroenterol Hepatol. 2011;26(Suppl 1):213-9

8. Qiu W, Wang X, Leibowitz B, Yang W, Zhang L, Yu J. PUMAmediated apoptosis drives chemical hepatocarcinogenesis in mice. Hepatology 2011;54:1249-58.

9. Wree A, Johnson CD, Font-Burgada J, Eguchi A, Povero D, Karin $\mathrm{M}$, et al. Hepatocyte-specific Bid depletion reduces tumor development by suppressing inflammation-related compensatory proliferation. Cell Death Differ 2015;22:1985-94.
10. Brem EA, Letai A. BOK: Oddball of the BCL-2 Family. Trends Cell Biol 2016;26:389-90.

11. Hsu SY, Kaipia A, McGee E, Lomeli M, Hsueh AJ. Bok is a proapoptotic Bcl-2 protein with restricted expression in reproductive tissues and heterodimerizes with selective anti-apoptotic Bcl-2 family members. Proc Natl Acad Sci USA 1997;94:12401-6.

12. Inohara N, Ekhterae D, Garcia I, Carrio R, Merino J, Merry A, et al. Mtd, a novel Bcl-2 family member activates apoptosis in the absence of heterodimerization with Bcl-2 and Bcl-XL. J Biol Chem 1998;273:8705-10.

13. Bartholomeusz G, Wu Y, Ali Seyed M, Xia W, Kwong KY, Hortobagyi G, et al. Nuclear translocation of the pro-apoptotic Bcl-2 family member Bok induces apoptosis. Mol Carcinog 2006;45:73-83.

14. Ray JE, Garcia J, Jurisicova A, Caniggia I. Mtd/Bok takes a swing: proapoptotic $\mathrm{Mtd} / \mathrm{Bok}$ regulates trophoblast cell proliferation during human placental development and in preeclampsia. Cell Death Differ 2010;17:846-59.

15. Echeverry N, Bachmann D, Ke F, Strasser A, Simon HU, Kaufmann T. Intracellular localization of the BCL-2 family member BOK and functional implications. Cell Death Differ 2013;20:785-99.

16. Moravcikova E, Krepela E, Donnenberg VS, Donnenberg AD, Benkova K, Rabachini $\mathrm{T}$, et al. BOK displays cell deathindependent tumor suppressor activity in non-small-cell lung carcinoma. Int J Cancer 2017;141:2050-61.

17. Schulman JJ, Wright FA, Kaufmann T, Wojcikiewicz RJ. The Bcl-2 protein family member Bok binds to the coupling domain of inositol 1,4,5-trisphosphate receptors and protects them from proteolytic cleavage. J Biol Chem 2013;288:25340-9.

18. D'Orsi B, Engel T, Pfeiffer S, Nandi S, Kaufmann T, Henshall DC, et al. Bok Is not pro-apoptotic but suppresses poly ADPribose polymerase-dependent cell death pathways and protects against excitotoxic and seizure-induced neuronal injury. J Neurosci 2016;36:4564-78.

19. Llambi F, Wang YM, Victor B, Yang M, Schneider DM, Gingras $\mathrm{S}$, et al. BOK Is a non-canonical BCL-2 family effector of apoptosis regulated by ER-associated degradation. Cell 2016;165:421-33.

20. Schulman JJ, Wright FA, Han X, Zluhan EJ, Szczesniak LM, Wojcikiewicz RJ. The stability and expression level of Bok are governed by binding to inositol 1,4,5-trisphosphate receptors. J Biol Chem 2016;291:11820-8.

21. Ke F, Voss A, Kerr JB, O'Reilly LA, Tai L, Echeverry N, et al. BCL-2 family member BOK is widely expressed but its loss has only minimal impact in mice. Cell Death Differ 2012;19:915-25.

22. Carpio MA, Michaud M, Zhou W, Fisher JK, Walensky LD, Katz SG. BCL-2 family member BOK promotes apoptosis in response to endoplasmic reticulum stress. Proc Natl Acad Sci USA 2015;112:7201-6.

23. Ke F, Bouillet P, Kaufmann T, Strasser A, Kerr J, Voss AK. Consequences of the combined loss of BOK and BAK or BOK and BAX. Cell Death Dis 2013;4:e650.

24. Ke F, Grabow S, Kelly GL, Lin A, O’Reilly LA, Strasser A. Impact of the combined loss of BOK, BAX and BAK on the hematopoietic system is slightly more severe than compound loss of BAX and BAK. Cell Death Dis 2015;6:e1938.

25. Tuzlak S, Kaufmann T, Villunger A. Interrogating the relevance of mitochondrial apoptosis for vertebrate development and postnatal tissue homeostasis. Genes Dev 2016;30:2133-51.

26. Beroukhim R, Mermel CH, Porter D, Wei G, Raychaudhuri S, Donovan J, et al. The landscape of somatic copy-number alteration across human cancers. Nature 2010;463:899-905.

27. Verna L, Whysner J, Williams GM. N-nitrosodiethylamine mechanistic data and risk assessment: bioactivation, DNA- 
adduct formation, mutagenicity, and tumor initiation. Pharmacol Ther 1996;71:57-81.

28. Cory S, Huang DC, Adams JM. The Bcl-2 family: roles in cell survival and oncogenesis. Oncogene 2003;22:8590-607.

29. Fernandez-Marrero Y, Bleicken S, Das KK, Bachmann D, Kaufmann T, Garcia-Saez AJ. The membrane activity of BOK involves formation of large, stable toroidal pores and is promoted by cBID. FEBS J 2017;284:711-24.

30. Einsele-Scholz S, Malmsheimer S, Bertram K, Stehle D, Johanning J, Manz M, et al. Bok is a genuine multi-BH-domain protein that triggers apoptosis in the absence of Bax and Bak. J Cell Sci 2016;129:2213-23.

31. Fernandez-Marrero Y, Ke F, Echeverry N, Bouillet P, Bachmann $\mathrm{D}$, Strasser A, et al. Is BOK required for apoptosis induced by endoplasmic reticulum stress? Proc Natl Acad Sci USA 2016;113: E492-E493.

32. Das M, Garlick DS, Greiner DL, Davis RJ. The role of JNK in the development of hepatocellular carcinoma. Genes Dev 2011;25:634-45.

33. Weber A, Boger R, Vick B, Urbanik T, Haybaeck J, Zoller S, et al. Hepatocyte-specific deletion of the antiapoptotic protein myeloid cell leukemia-1 triggers proliferation and hepatocarcinogenesis in mice. Hepatology 2010;51:1226-36.

34. Gillet R, Grimber G, Cavard C, Bennoun M, Mignon A, Briand P, et al. Effect of Bcl-2 expression on hepatic preneoplasia in mice. Cancer Lett 2002;177:189-95.

35. Labi V, Erlacher M, Krumschnabel G, Manzl C, Tzankov A, Pinon J, et al. Apoptosis of leukocytes triggered by acute DNA damage promotes lymphoma formation. Genes Dev 2010;24:1602-7.

36. Michalak EM, Vandenberg CJ, Delbridge AR, Wu L, Scott CL, Adams JM, et al. Apoptosis-promoted tumorigenesis: gammairradiation-induced thymic lymphomagenesis requires Pumadriven leukocyte death. Genes Dev 2010;24:1608-13.
37. Pierce RH, Vail ME, Ralph L, Campbell JS, Fausto N. Bcl-2 expression inhibits liver carcinogenesis and delays the development of proliferating foci. Am J Pathol 2002;160:1555-60.

38. Cicero S, Herrup K. Cyclin-dependent kinase 5 is essential for neuronal cell cycle arrest and differentiation. J Neurosci 2005;25:9658-68.

39. Ogara MF, Belluscio LM, de la Fuente V, Berardino BG, Sonzogni SV, Byk L, et al. CDK5-mediated phosphorylation of p19INK4d avoids DNA damage-induced neurodegeneration in mouse hippocampus and prevents loss of cognitive functions. Biochim Biophys Acta 2014;1843:1309-24.

40. Guan KL, Jenkins CW, Li Y, O'Keefe CL, Noh S, Wu X, et al. Isolation and characterization of p19INK4d, a p16-related inhibitor specific to CDK6 and CDK4. Mol Biol Cell 1996;7:57-70.

41. Ceruti JM, Scassa ME, Flo JM, Varone CL, Canepa ET. Induction of p19INK4d in response to ultraviolet light improves DNA repair and confers resistance to apoptosis in neuroblastoma cells. Oncogene 2005;24:4065-80.

42. Morishita A, Gong J, Deguchi A, Tani J, Miyoshi H, Yoshida H, et al. Frequent loss of p19INK4D expression in hepatocellular carcinoma: relationship to tumor differentiation and patient survival. Oncol Rep 2011;26:1363-8.

43. Hui L, Zatloukal K, Scheuch H, Stepniak E, Wagner EF. Proliferation of human HCC cells and chemically induced mouse liver cancers requires JNK1-dependent p21 downregulation. J Clin Invest 2008;118:3943-53.

44. Wu H, Wade M, Krall L, Grisham J, Xiong Y, Van Dyke T, et al. Targeted in vivo expression of the cyclin-dependent kinase inhibitor p21 halts hepatocyte cell-cycle progression, postnatal liver development and regeneration. Genes Dev 1996;10:245-60.

45. Rosner M, Hengstschlager M. Cytoplasmic and nuclear distribution of the protein complexes mTORC1 and mTORC2: rapamycin triggers dephosphorylation and delocalization of the mTORC2 components rictor and sin1. Hum Mol Genet 2008;17:2934-48. 